\title{
Planning and designing of intelligent medical logistics system
}

\author{
Rongxia Zhou, Shih-Ming Ou
}

\begin{abstract}
This paper aims to investigate the influence relationship and mechanism of influencing factors of the intelligent medical logistics system. Firstly, through literature reviews, we constructed the hierarchical structure consists of 18 factors. Secondly, we conducted questionnaires to acquire the experts' assessments of the influence between every two factors. Then, the fuzzy decision-making trial and evaluation laboratory (F-DEMATEL) was employed to obtain the total influence values and the net influence values that could be used to draw a visual causal map. The results show that "The practicability of the logistics platform", "the management level of the intelligent medical logistics platform" and "the different needs for medical logistics from various customers" are the top three in terms of total influence value and net influence value, Therefore, they can be regarded as crucial factors. When developing an intelligent medical logistics system, it is necessary to take the actual situation into account to build an intelligent medical logistics platform.
\end{abstract}

Index Terms-Medical logistics, Intelligent logistics, F-DEMATEL

\section{INTRODUCTION}

Since the reform and opening up, China has continued to promote reforming and improving the medical industry, thus making remarkable progress in the medical and health undertakings. However, the net profit margin of medical circulation enterprises has been further compressed due to the stagnation of the pharmaceutical market and the country's bidding policy. Furthermore, the new laws and regulations have imposed stricter requirements on the medical circulation enterprises, causing the costs of the circulation enterprises to rise continuously. These have inevitably affected the development of medical circulation enterprises. Besides, the various links and complexity of medical logistics have caused relatively severe medical losses and consequences due to poor environmental monitoring, improper storage, shipping errors, etc. Therefore, under the dual pressure of falling net profit and increasing costs, the medical circulation enterprises, especially the medical circulation logistics enterprises, need to integrate medical logistics to effectively reduce overall costs and provide better services to enhance their competitiveness.

The rapid development of the new-generation information technology represented by the Internet, big data, artificial intelligence, etc. has brought new opportunities for the development of the medical industry. The deep integration of information technology and the medical industry has become

Rongxia Zhou, Department of Logistics Management, Fujian Jiangxia University, Fuzhou, China.

Shih-Ming Ou, Department of Logistics Management, Fujian Jiangxia University, Fuzhou, China an irreversible trend, thereby promoting the transformation and upgrading of medical logistics. Such a background has generated "intelligent medical logistics." However, as a new thing, intelligent medical logistics still faces prominent contradictions and problems in terms of ideological cognition, cost issues, infrastructure equipment, technical level, market factors, etc. When designing an intelligent medical logistics system, it is impossible to consider multiple factors but to grasp the key points. Based on many contradictions and problems, an influencing factor system for the design and implementation of the intelligent medical logistics system was established by this study. Fuzzy DEMATEL was used to build a corresponding analysis model of the influencing factors, and the key factors affecting the intelligent medical logistics system design were selected. The objects are to provide a decision-making reference for designing an intelligent medical logistics system and promoting the reformation of the medical and health care industry.

\section{ANALYSIS OF THE INFLUENCING FACTORS WHEN DESIGNING AN INTELLIGENT MEDICAL LOGISTICS SYSTEM}

The design and implementation of the intelligent medical logistics system is a sophisticated system engineering that involves many multi-party benefits and is affected by many factors. Based on the actual development of intelligent medical logistics and relevant literature, 10 experts in the medical logistics management field were invited by this study to conduct in-depth interviews, and four dimensions, namely: operation management, urban traffic pressure, intelligent medical logistics service quality, and service efficiency of the intelligent medical logistics platform were finally determined to analyze the factors affecting the intelligent medical logistics system design.

\section{A. Operation management of the intelligent medical logistics platform}

The practicality, maintenance, information network technology, and management level of the intelligent medical logistics platform will directly affect the intelligentization of the medical logistics system.

\section{B. Urban traffic pressure}

Following the continuous advancement of the modernization process and the constant rise in the number of vehicles, some cities have gradually experienced severe congestion, poor traffic, and other problems. They have inevitably affected the efficiency of medical logistics transportation and distribution, and further influenced the intelligent of medical logistics. 


\section{Service quality of intelligent medical logistics}

Under an increasingly fierce market competition environment, how to improve the service quality and level of the intelligent logistics system is the original intention of designing an intelligent medical logistics system. The quality and level of logistics services can be reflected by customer satisfaction with the services, different needs for medical logistics from various customers, working attitude of logistics personnel, and the degree of corporate investment.

\section{Service benefits of intelligent medical logistics}

The degree of ability of logistics personnel on the characteristics of medicinal products, the degree of protection on the products, the connectivity of all aspects of logistics activities, and the degree of acceptance of customers on intelligent medical logistics will affect the efficiency of the intelligent medical logistics services. All of the above factors should be taken into account.

Based on the analysis of the influencing factors on the intelligent medical logistics system design, the influencing factor system of the intelligent medical logistics design was preliminarily established by this paper, which included 18 factors in six dimensions as shown in Table 1:

Table 1. Influencing factors of the intelligent medical logistics system

\begin{tabular}{|c|c|}
\hline & logistics system \\
\hline Dimensions & Influencing factors \\
\hline \multirow{4}{*}{$\begin{array}{l}\text { Operation } \\
\text { management of the } \\
\text { intelligent medical } \\
\text { logistics platform }\end{array}$} & $\begin{array}{l}\text { The practicality of the intelligent medical logistics } \\
\text { platform (F1) }\end{array}$ \\
\hline & $\begin{array}{l}\text { Maintenance of the intelligent medical logistics platform } \\
\text { (F2) }\end{array}$ \\
\hline & Intelligent information network technology (F3) \\
\hline & $\begin{array}{l}\text { Management level of the intelligent medical logistics } \\
\text { platform (F4) }\end{array}$ \\
\hline \multirow{4}{*}{$\begin{array}{l}\text { Urban } \\
\text { pressure }\end{array}$} & Urban population base (F5) \\
\hline & Urban traffic congestion (F6) \\
\hline & Urban travel route layout (F7) \\
\hline & Urban road conditions (F8) \\
\hline \multirow{4}{*}{$\begin{array}{l}\text { Service quality of } \\
\text { the intelligent } \\
\text { medical logistics }\end{array}$} & Customer satisfaction with the logistics services (F9) \\
\hline & $\begin{array}{l}\text { Different customer needs for medical logistics from } \\
\text { various customers (F10) }\end{array}$ \\
\hline & The working attitude of the logistics personnel (F11) \\
\hline & Degree of corporate investment (F12) \\
\hline \multirow{6}{*}{$\begin{array}{l}\text { Service benefits of } \\
\text { the intelligent } \\
\text { medical logistics }\end{array}$} & $\begin{array}{l}\text { Degree of ability of logistics personnel on the } \\
\text { characteristics of medicinal products (F13) }\end{array}$ \\
\hline & $\begin{array}{l}\text { Degree of protection of the medicinal products during } \\
\text { the logistics process (F14) }\end{array}$ \\
\hline & $\begin{array}{l}\text { The cohesiveness of various parts of medical logistics } \\
\text { activities (F15) }\end{array}$ \\
\hline & $\begin{array}{l}\text { Customer acceptance on the intelligent medical logistics } \\
\text { (F16) }\end{array}$ \\
\hline & $\begin{array}{l}\text { Integration of the intelligent medical logistics platform } \\
\text { (F17) }\end{array}$ \\
\hline & Price positioning (F18) \\
\hline
\end{tabular}

To sum up, many factors are affecting the intelligent medical logistics system design, and there are correlations and influences between the factors, so it is difficult to clarify the relationship between these factors directly. The use of the fuzzy DEMATEL method to quantitatively analyze the influencing factors of the intelligent medical logistics system design is possible to compare scientifically and judge the relationship between the primary and secondary factors and identify the mutual influence relationship. Hence, the Fuzzy DEMATEL method was introduced by this paper to construct an influencing factor model of intelligent medical logistics system design, and then attempt to screen out the critical influencing factors through quantitative analysis.

\section{CONSTRUCTION OF THE INFLUENCING FACTOR ANALYSIS MODEL OF AN INTELLIGENT MEDICAL LOGISTICS SYSTEM DESIGN}

To solve the factor correlation in real society, Gabus and Fontela of the Butler Association of the Geneva Research Center of the United States proposed the DEMATEL method in the 1970s. Such method analyzes the system elements based on the graph theory and matrix tool, and judges the correlation among the factors and their contribution to the target, and further identifies the key factors from many influencing factors to provide the logical decision basis on the related issues. The DEMATEL method is limited to the real number field in expressing the factors, and it is difficult to accurately evaluate the relationship between the complexity and the ambiguity of the system factors. Fuzzy DEMATEL, on the other hand, can convert the fuzzy statements scored by the experts and scholars on factor relationships into clear numerical values to create more accurate influencing results. It can thus effectively eliminate the deficiency of the DEMATEL method and improve the objectivity and effectiveness of the research. So, Fuzzy DEMATEL was adopted by this paper to explore the influencing factors of the intelligent medical logistics system design. The main steps are as follows:

\section{A. Establishing a scientific indicator system of influencing factors}

As shown in Table 1 above, the indicator system of the influencing factors of the intelligent medical logistics system design includes a total of 18 indicators in four dimensions.

\section{B. Obtaining a fuzzy direct influence matrix}

Industry experts and scholars were invited to form an expert advisory group. The influential relationship among various factors was judged by the respondents based on their cognitive level and practical experience, and the semantic codes were filled in the corresponding positions of the questionnaire. A five-scale semantic variable was used by the questionnaire to describe the relationship between the factors, as shown in Table 2. EXCEL was used to analyze and collate the questionnaire data filled out by the experts, and the direct fuzzy influence matrix was then obtained.

Table 2. The relationship between the semantic variables and triangular fuzzy numbers

\begin{tabular}{l|c|c}
\hline $\begin{array}{l}\text { Influence Rating } \\
\text { Standards }\end{array}$ & Semantic code & $\begin{array}{c}\text { Triangular Fuzzy Number } \\
\text { (TFN) }\end{array}$ \\
\hline No influence & NO & $(0.00,0.00,0.25)$ \\
\hline Very low influence & VL & $(0.00,0.25,0.50)$ \\
\hline Low influence & V & $(0.25,0.50,0.75)$ \\
\hline High influence & H & $(0.50,0.75,1.00)$ \\
\hline Very high influence & VH & $(0.75,1.00,1.00)$ \\
\hline
\end{tabular}

\section{Calculating the initial influence matrix}

As the semantic variables cannot be directly calculated, the fuzzy influence matrix must be obtained according to Table 2, and the fuzzy numbers were then converted into the exact numerical method (CFCS). The fuzzy influence matrix was defuzzified to establish the initial influence matrix $\mathrm{Z}$ (due to 
limited space, the defuzzification step of CFCS was omitted). Assuming there was $\mathrm{p}$ number of experts and $\mathrm{n}$ number of influencing factors, the initial influence matrix can be expressed as follows. Please see equations (1) and (2).

$$
\begin{gathered}
Z=\left[z_{i j}\right]_{n \times n} \\
z_{i j}=\frac{1}{p} \sum_{k=1}^{p} z_{i j}^{k}
\end{gathered}
$$

In equation (2), $z_{i j}^{k}$ indicates the influence value of the kth expert's reflected factor $\mathrm{i}$ on the quantitative factor $\mathrm{j}$.

\section{Calculating the comprehensive influence matrix}

Step 1. The initial influence matrix was standardized to obtain the influence matrix, and the influence matrix $X=\left[x_{i j}\right]_{n \times n}$ was obtained. The standardized equation is as follow:

$$
X=\frac{z_{i j}}{\operatorname{maX}_{1 \leq i \leq n} \sum_{j=1}^{n} z_{i j}}
$$

Step 2. The comprehensive influence matrix $\mathrm{T}$ was calculated, where I is the unit matrix.

$$
T=X(1-X)^{-1}=\left[t_{i j}\right]_{n \times n}
$$

E. Drawing a causal coordinate diagram to screen the key factors

Through the comprehensive influence matrix, the influencing degree $\mathrm{D}$ and the affected degree $\mathrm{R}$, the centrality $(D+R)$, and the reasoning degree (D-R) of each factor were calculated, as shown in equations (5) and (6). The centrality was taken as the horizontal axis and the reasoning degree as the vertical axis. A causal diagram that reflected the complicated relationship between the factors was drawn, the importance of each factor in the system was determined, and the key influencing factors were selected.

$$
\begin{aligned}
& D_{i}=\sum_{j=1}^{n} t_{i j} \\
& R_{i}=\sum_{i=1}^{n} t_{i j}
\end{aligned}
$$

\section{SELECTING THE KEY INFLUENCING FACTORS OF THE INTELLIGENT MEDICAL LOGISTICS SYSTEM DESIGN}

Based on the needs of the research, 10 authoritative experts and scholars in the field of medical logistics was interviewed by the research team, and the relationship among the 18 influencing factors was judged and graded by these 10 experts. A simple analysis and sorting was conducted on the data using EXCEL, and the data was processed and analyzed by CFCS and DAMATEL methods. The comprehensive influence matrix, effected degree, centrality, and reasoning degree of each factor were then obtained. The key factors affecting the intelligent medical logistics system design was finally screened and obtained.

\section{A. Determining the initial influence matrix}

EXCEL was adopted to perform an analysis and sorting on the expert graded data, and the triangular fuzzy numbers between the influencing factors of the intelligent medical

\begin{tabular}{|c|c|c|c|c|c|c|c|c|c|c|c|c|c|c|c|c|c|c|}
\hline Initial & $\mathrm{F} 1$ & $\mathrm{~F} 2$ & $F 3$ & F4 & F5 & F6 & F7 & F8 & F9 & F10 & F11 & F12 & F13 & F14 & F15 & F16 & F17 & F18 \\
\hline F1 & 0 & 2.8 & 3 & 2.8 & 1.2 & 1.4 & 1.8 & 1 & 3.4 & 2.4 & 2 & 3 & 2.4 & 3 & 3.2 & 3.2 & 2.6 & 2.6 \\
\hline $\mathrm{F} 2$ & 3.4 & & 2.6 & 2.6 & 1 & 1.2 & 1 & 1.2 & 3.4 & 2 & 1.6 & 3.2 & 2 & 2.6 & 2 & 2 & 2 & \\
\hline F3 & 3.2 & 3.2 & 0 & 3 & 1 & 1.4 & 1.6 & 1.2 & 1.3 & 1.4 & 1.8 & 3.4 & 1.6 & 1.8 & 3.4 & 2 & 3.2 & 2.6 \\
\hline F4 & 3 & 2.4 & 2 & 0 & 0.6 & 0.8 & 2.2 & & 3.8 & 2.6 & 2.4 & & 2.4 & & 3.2 & 3.2 & 2.8 & 2.6 \\
\hline F5 & 3 & 2.4 & 2.2 & 2.8 & 0 & 3.6 & 2.8 & 3 & 2.2 & 2.6 & 1.6 & 3.2 & 1 & 1.2 & 1.2 & 2 & 1.6 & 1.2 \\
\hline F6 & 2.6 & 2 & 1.2 & 1.8 & 2.6 & 0 & 3.6 & 3.4 & 2.4 & 0.4 & 1.8 & 2 & 2 & 0.4 & 2 & 2.2 & 2 & 2 \\
\hline F7 & 2.6 & 2.4 & 1.6 & 2.2 & 1.2 & 2.2 & 0 & 2.8 & 2 & 1 & 1.2 & 1.4 & 0.4 & 2 & 2.4 & 2 & 2.2 & 2 \\
\hline F8 & 2 & 2 & 1.8 & 2 & 1.8 & 2.4 & 3.8 & 0 & 2.6 & 1 & 2 & 2.6 & 0.2 & 2.8 & 2.4 & 1.4 & 2 & 2 \\
\hline F9 & 2.8 & 3 & 2 & 3.4 & 1.2 & & 0.8 & 0.4 & 0 & 1.6 & 2.2 & 2.8 & 1.8 & 2.6 & 2.2 & 2.8 & 2.6 & 2.4 \\
\hline F10 & 3.2 & 3.2 & 2.4 & 3.8 & 1 & 1 & 1.2 & 0.8 & 3.6 & 0 & 2.6 & 2.6 & 3.2 & 3 & 2 & 2.8 & 2.4 & 2 \\
\hline F11 & 1.2 & 1.4 & 0.8 & 2.4 & 0.4 & 0.4 & 0.8 & 0.6 & 3 & 2 & 0 & 1.6 & 2 & 2.8 & 0.8 & 3 & 1 & 1 \\
\hline F12 & 3.4 & 3.4 & 3.4 & 3.4 & 1.2 & 0.2 & 1 & 0.2 & 2 & 1.2 & 2.2 & 0 & 1.6 & 2.4 & 2.8 & 1.8 & 3 & 2.6 \\
\hline F13 & 1.2 & 1.4 & 0.2 & 1.6 & 0.2 & 0 & 0 & 0.3 & 3.2 & 2 & 2.8 & 2.2 & 0 & 3.4 & 2.4 & 3 & 2 & 1.8 \\
\hline F14 & 1 & 1.2 & 1.5 & 1.8 & 0.2 & 0 & 1 & 0.2 & 3.8 & 2.4 & 2 & 3.2 & 1.4 & 0 & 2.2 & 3.4 & 2 & 2 \\
\hline F15 & 4 & 2.4 & 2.8 & 2.2 & 0 & 0 & 0.8 & 0.2 & 3.2 & 2.2 & 1.4 & 2.6 & 1.4 & 2.8 & 0 & 2.6 & 3.2 & 3.4 \\
\hline F16 & 2.8 & 2.8 & 2.6 & 3.4 & 0.4 & 0.4 & 0.4 & 0.2 & 3.2 & 1.8 & 2.6 & 3.6 & 1.2 & 2.4 & 3.6 & 0 & 3.2 & 2.8 \\
\hline F17 & 3.8 & 3.6 & 3.6 & 3.8 & 0.2 & 0.8 & 1 & 0.4 & 3.4 & 1.2 & 2.4 & 3.6 & 1 & 3 & 3.8 & 2.6 & 0 & 3.6 \\
\hline F18 & 2.8 & 1.6 & 1.4 & 2.8 & 0.2 & 0.4 & 0.4 & & & 1.6 & & 2.2 & & 3.4 & 3.8 & 3.2 & 3.2 & \\
\hline
\end{tabular}
logistics system design was obtained. The CFCS method was then used to defuzzify the initial influence matrix. Please see Table 3 for details:

Table 3. Initial influence matrix $\mathrm{Z}$ of the influencing factors on the intelligent medical logistics system design

\section{B. Determining the comprehensive influence matrix}

Based on equations (3) and (4), the comprehensive influence matrix $\mathrm{T}$ was calculated, as shown in Table 4:

Table 4. Comprehensive influence matrix $\mathrm{Z}$ of the influencing factors of the intelligent medical logistics system design

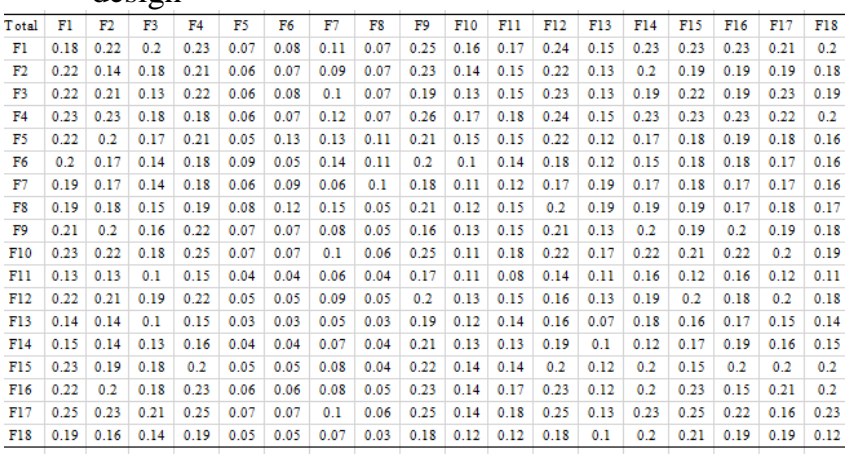

\section{Establishing a causal relationship diagram}

Based on the comprehensive influence matrix and equations (5) and (6), the influencing degree and the effected degree of each factor were calculated. Hence, the centrality (D+R) value affecting the design-related factors of the intelligent medical logistics system and the reasoning degree (D-R) value was then determined, as shown in Table 5 below: Table 5. Score of each influencing factor in the intelligent medical logistics system design

\begin{tabular}{r|r|r|r|r}
\hline $\begin{array}{c}\text { Influencing } \\
\text { factors }\end{array}$ & $\begin{array}{c}\text { Influencing } \\
\text { degree(D) }\end{array}$ & $\begin{array}{l}\text { Effected } \\
\text { degree ( R ) }\end{array}$ & $\begin{array}{l}\text { Centrality } \\
\text { degree ( } \\
\text { D+R ) }\end{array}$ & $\begin{array}{c}\text { Reasoning } \\
\text { degree ( D-R } \\
\text { ) }\end{array}$ \\
\hline F1 & 4.33 & 2.62 & 6.93 & 1.71 \\
\hline F2 & 2.86 & 3.34 & 6.2 & -0.48 \\
\hline F3 & 2.94 & 2.86 & 5.8 & 0.08 \\
\hline F4 & 4.25 & 2.59 & 6.84 & 1.66 \\
\hline F5 & 2.95 & 1.06 & 4.01 & 1.89 \\
\hline F6 & 2.66 & 1.22 & 3.88 & 1.44 \\
\hline F7 & 2.61 & 1.68 & 4.29 & 0.93 \\
\hline F8 & 2.88 & 1.1 & 3.98 & 1.78 \\
\hline F9 & 3.2 & 3.5 & 6.7 & -0.3 \\
\hline F10 & 3.15 & 2.35 & 5.5 & 0.8 \\
\hline
\end{tabular}




\begin{tabular}{r|r|r|r|r}
\hline F11 & 1.97 & 2.65 & 4.62 & -0.68 \\
\hline F12 & 2.8 & 3.64 & 6.44 & -0.84 \\
\hline F13 & 2.15 & 2.36 & 4.51 & -0.21 \\
\hline F14 & 2.32 & 3.43 & 5.75 & -1.11 \\
\hline F15 & 2.79 & 3.49 & 6.28 & -0.7 \\
\hline F16 & 2.96 & 3.43 & 6.39 & -0.47 \\
\hline F17 & 3.28 & 3.33 & 6.61 & -0.05 \\
\hline F18 & 2.49 & 3.12 & 5.61 & -0.63 \\
\hline
\end{tabular}

The (D+R) values in the above table were plotted on the horizontal axis, and the (D-R) values were plotted on the vertical axis to construct a causal relationship among the factors affecting the intelligent medical logistics system design, as shown in Fig. 1:

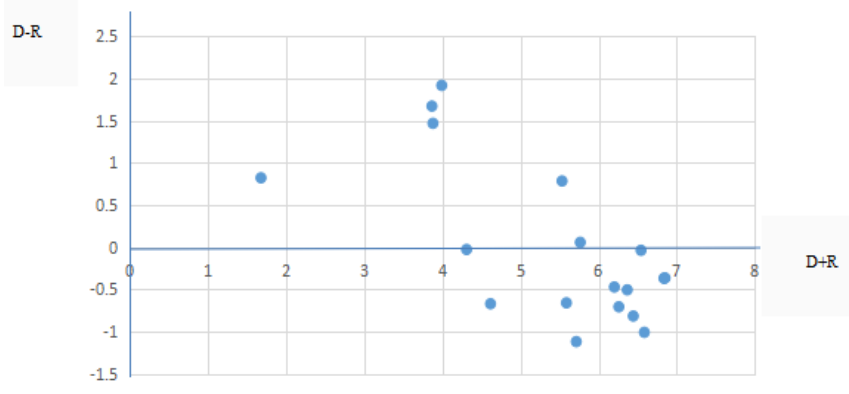

Fig. 1 Causal relationship diagram

\section{Analytical results}

As shown in the causal diagram above, if the average arithmetic value (5.391) of centrality (D+R) is taken as the vertical axis, it can divide the causal relationship diagram into four quadrants. The first quadrant represents the core factor area with high centrality (D+R) and reasoning degree ( D-R). The factors in this quadrant are known as the key influencing factors and should be listed as the priority objects. The second quadrant represents the driving factor area, which has a low centrality $(D+R)$ and a high reasoning degree (D-R). Its high independence will affect other minority factors. The third quadrant indicates the independent factor area, where its centrality $(D+R)$ and reasoning degree $(D-R)$ is low, and the interaction with other factors is also low. So, as long as the factors in this area are controlled well, it will be fine. The fourth quadrant indicates the affected factor area, and its centrality $(D+R)$ is high, and the reasoning degree (D-R) is low. The factors in this quadrant need to be managed urgently, and cannot be improved directly, but improved through managing the factors in the first quadrant and the second quadrant. The characteristics of each influencing factor are shown in Fig. 2:

\begin{tabular}{|c|c|}
\hline $\begin{array}{l}\text { 2nd quadrant: Driver factor area } \\
\text { F5 Urban population base } \\
\text { F6 Urban traffic congestion } \\
\text { degree } \\
\text { F7 Urban travel route layout } \\
\text { F8 Urban road conditions }\end{array}$ & $\begin{array}{l}\text { 1st quadrant: Core factor } \\
\text { area } \\
\text { F1 Practicality of the } \\
\text { intelligent medical } \\
\text { logistics platform } \\
\text { F4 Management level of the } \\
\text { intelligent medical } \\
\text { logistics platform } \\
\text { F10 Different needs for } \\
\text { medical logistics from } \\
\text { various customers }\end{array}$ \\
\hline $\begin{array}{l}\text { 3rd quadrant: Independent } \\
\text { factor area } \\
\text { F11 Working attitude of the }\end{array}$ & $\begin{array}{l}\text { 4th quadrant: Affected } \\
\text { factor area } \\
\text { F2 Maintenance of the }\end{array}$ \\
\hline
\end{tabular}

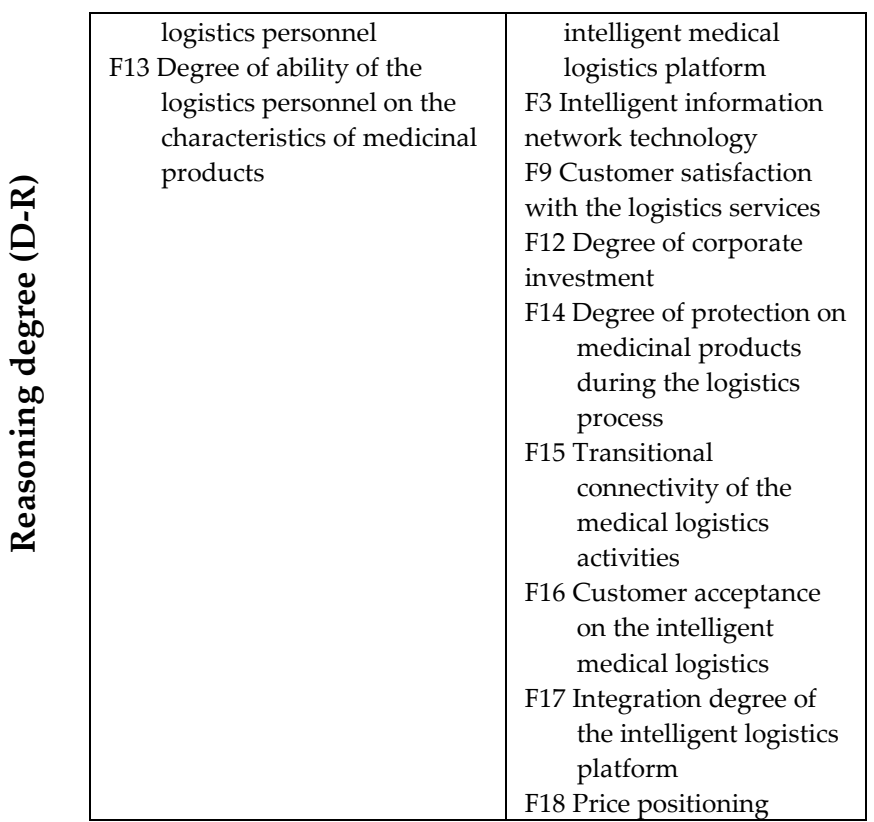

Fig. 2 Characteristic classification diagram

As shown in Fig. 2, the key influencing factors of the intelligent medical logistics system design are: the practicality of the intelligent medical logistics platform (F1), the management level of the intelligent medical logistics platform (F4), and the different needs for medical logistics from various customers (F10). The driving factors of the intelligent medical logistics system design are: urban population base (F5), urban traffic congestion (F6), urban travel route layout (F7), and urban road conditions (F8). The independent factors of the intelligent medical logistics system design are: the working attitude of the logistics personnel (F11), and the degree of ability of the logistics personnel on the characteristics of medicinal products (F13). The factors in this sector are not easily affected by other factors, and unlikely to cause any influences to other factors also. The maintenance of the intelligent medical logistics platform (F2), the intelligent information network technology (F3), customer satisfaction with the logistics services (F9), and other nine factors are the affected factors. These factors are highly susceptible to other factors, and urgently need to be highly valued.

\section{CONCLUSIONS}

An influencing factor analysis model for the intelligent medical logistics system design was established by collecting and analyzing the relevant data. The fuzzy DEMATEL method was used by this paper to analyze the causal relationship among the various influencing factors, and the key influencing factors were eventually selected. They are: the practicability of the logistics platform, the management level of the intelligent medical logistics platform, and the different needs for medical logistics from various customers. Therefore, when developing the intelligent medical logistics system platform, it is necessary to combine the actual situation of medical logistics based on a full investigation, analysis, and research to build an intelligent medical logistics platform with high-cost performance, practicability, and applicability. Regarding the management of the medical logistics platform, it is essential to strengthening the 
maintenance, management, and supervision of the platform to ensure it can be operated steadily and orderly. Also, amid fierce competition in the medical logistics industry, if the medical circulation enterprises wish to have a strong foothold in the market, they must fully consider the differences in customer needs and develop different medical logistics delivery solutions for various customers.

\section{REFERENCES}

[1] Y. J. Wu and G. M. Zhao "Research on Identifying Critical Factors of Promoting Service Capability for Service Integrator-Fuzzy DEMATEL Method," Sci. Manage. Res., vol. 4, 2014, pp. 221-225

[2] W. B. Liu and M. Y. Zhang "Analysis of Critical Infrastructures Association under Disaster Environment Based on Fuzzy DEMATEL," J. Natural Disasters, vol.2, 2018, pp.88-95.

[3] Y. W. Du and S. S. Wang "Fuzzy DEMATEL Comprehensive Evaluation Method for Science Fund," Project of National Natural Science Foundation of China, Vol.9, 2017, pp.161-169.

[4] X. L. Cui, C. Y. Wu and L Zhang "Applied Technology Analysis of the Internet and Cloud Computing in the Field of Intelligent Medical.Patent Examination Cooperation Henan Center of the Patent Office", 2018.

[5] D. Zhang, "Research on Intelligent Dispatching Platform of Medical Track Logistics System," Nanjing University of Aeronautics and Astronautics, Nanjing Jiangsu China, 2017.

[6] T. Z. Liu and A. Z. Shen "SPD-based Logistics Management Process Optimization Strategy of the Medical Consumables," Chinese Health Ser. Manage., vol.2, 2017, pp.114-116.

[7] S. X. Yao and X. D. Li "A New DEMATEL-based Information Security Risk Factor Analysis Method," Inform. Commun., Vol.8, 2015, pp.107-109

[8] Y. Ding Yon, "Design and Implementation of Environmental Monitoring System for Low-temperature Food Transportation Process," Zhejiang University of Technology, Zhejiang, Hangzhou, China, 2014.

[9] W. Yang Wei and P. Dang, "Medicine Cold Chain Logistics System Construction Based on Cloud Computing," Manufacturing Auto., Vol.24, 2014, pp.6-9.

Rongxia Zhou is a lecturer at Fujian Jiangxia University in China. She holds a master's degree from Wuhan University of Science and Technology. She has chaired and participated in 8 department-level projects and in 3 provincial-level projects. She has published more than ten papers in international journals.

Shih-Ming Ou is an Associate Professor of Logistics Administration at Fujian Jiangxia University in China. Shih-Ming is also acting as a consultant of Emerald, the largest electric bus power battery supplier in Taiwan. His research interests include operations research, operations management, innovation and technology management and differential game in marketing. Shih-Ming holds a Ph.D. degree from Chung Hua University, a MS from Case Western Reserve University, a MBA from National Defense Management Academy. 